Rev. salud pública. Sup. 8 (1): 24-32, 2006

\title{
Lepra Conyugal
}

\author{
Esperanza Meléndez ${ }^{1}$, Jairo Fuentes ${ }^{2}$ y Gerzaín Rodríguez ${ }^{3}$ \\ ${ }^{1}$ Médica. Especialista en Dermatología Programa de Control de Lepra, Barranquilla, Colombia. E-mail: \\ esmelend@yahoo.com \\ ${ }^{2}$ Médico. Especialista en Dermatología. Facultad de Medicina, Universidad Libre y Universidad San \\ Martín, Barranquilla, Colombia. \\ E-mail:afucal@hotmail.com \\ ${ }^{3}$ Médico, Especialista en Dermatopatologia. Facultad de Medicina, Universidad de la Sabana, Chia, \\ Colombia. \\ E-mail: gerzain_rodriguez@yahoo.com
}

Recibido 15 Septiembre 2005/Enviado para Modificación 23 Octubre 2005/Aceptado 19 Abril 2006

\section{RESUMEN}

Objetivos Determinar la ocurrencia de lepra entre cónyuges y precisar las características de la enfermedad en el caso índice y en el secundario.

Métodos Estudiamos sus características en una zona de la Costa Caribe colombiana (Departamento del Atlántico), durante 1980-2000, a través de la revisión de las historias clínicas del Programa Control de Lepra, del examen clínico y de entrevistas con los afectados.

Resultados Encontramos 26 parejas con lepra conyugal, que representan el $5,4 \%$ de los casos diagnosticados durante el periodo, con edades entre 20 y 89 años. El $65,4 \%$ de los casos índices fueron hombres y $22(84,6 \%)$ lepromatosos; dos tenían lepra indeterminada y dos tuberculoide. Los casos secundarios fueron tuberculoides en su mayoría (42,3\%) y, en conjunto, 61 $\%$ paucibacilares. Ningún caso índice paucibacilar se asoció con lepra multibacilar en el cónyuge. Sólo dos parejas tenían consanguinidad. Ninguno de los cónyuges llegó enfermo al matrimonio y su convivencia entre la aparición de la enfermedad en el caso índice y el secundario, varió entre 5 y 40 años. La convivencia de los cónyuges varió entre 5 y 44 años. Las discapacidades se presentaron con mayor frecuencia en los pies y fueron más graves en los casos índices lepromatosos, con enfermedad de larga evolución, que en los secundarios, porque éstos fueron paucibacilares con mayor frecuencia y se detectaron cuando su enfermedad tenía menor tiempo de evolución.

Conclusiones La lepra conyugal es poco frecuente, requiere varios años de convivencia para presentarse en el segundo cónyuge y es más común cuando el caso primario es lepromatoso. Cuando un cónyuge es paucibacilar su pareja no desarrollara lepra multibacilar 
Palabras Clave: Lepra, transmisión, Colombia, Costa Caribe (fuente: DeCS, BIREME).

\section{ABSTRACT \\ Conjugal leprosy}

Objectives Determining the occurrence of leprosy amongst couples and establishing the type of leprosy in index and secondary cases.

Methods The characteristics of leprosy were studied between 1980 and 2000 in Atlántico Department located on the Colombian Caribbean Coast. Clinical histories of patients registered in the Leprosy Control Programme were reviewed. Clinical exams were performed and personal interviews carried out with couples suffering from leprosy.

Results Twenty-six married couples were found to be suffering from leprosy, representing $5,4 \%$ of leprosy cases detected during the study period. They were aged from 20 to $89.65,4 \%$ of the index cases were men and $22(84,6$ $\%)$ were multibacillary, lepromatous cases; two had indeterminate leprosy and two were suffering from tuberculoid leprosy. Sixty-one percent of the secondary cases were paucibacillary patients, $42 \%$ of them being tuberculoid. No paucibacillary cases were associated with multibacillary leprosy in the couples. Only two couples had consanguinity. None of the couples had had leprosy at the time of being married. The time between leprosy being detected in index cases and the disease being detected in secondary patients varied from 5 to 40 years. Disabilities were more common in the feet and to a higher degree in lepromatous index cases who had had the disease for a longer time than the secondary cases because these were more frequently paucibacillary patients who had a disease having shorter evolution.

Conclusions In spite of ongoing, prolonged contact, conjugal leprosy is not frequent and requires several years to develop in the second person. Lepromatous leprosy in index cases was more frequently associated with leprosy in the couple. When the primary case was paucibacillary, no multibacillary leprosy occurred in the secondary case.

Key Words: leprosy, transmission, Colombia, Caribbean Coast (source: $\mathrm{MeSH}, \mathrm{NLM}$ ).

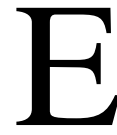
l paciente de lepra sin tratamiento es la fuente de infección para adquirir la enfermedad. El riesgo de adquirirla es más alto entre los convivientes de enfermos que entre la población general; es dos veces mayor para los convivientes con enfermos paucibacilares, entre 5 y 10 para los que lo hacen con enfermos multibacilares $(1,2)$ y de 4 para el contacto social (2). La mayoría de los contactos que desarrollaron lepra lo hicieron luego de más de 6 años del registro del caso primario (2). Entre 9598 contactos de 1614 casos de lepra en la India, se demostró que la tasa de inciden- 
cia de la enfermedad en ellos se mantuvo diez años después de comenzado el tratamiento del caso primario (3); durante el primer año fue de $3.8 \times 1000$ pacientes/año y después, 3 x 1000 pacientes/año (3). La rata de incidencia de lepra en los contactos intradomiciliarios fue más alta en los niños, que representaron un tercio de los casos nuevos (4). El riesgo de infección con $M$. leprae es mayor mientras más cerca se esté del caso primario: tres de los cuatro hijos menores de 7 años de una paciente lepromatosa desarrollaron lepra, dos de ellos también lepra multibacilar, mientras que tres de sus cinco sobrinos, que vivían en la misma casa, desarrollaron lepra paucibacilar; el esposo no presentó enfermedad (5).

En Malawi se demostró que la transmisión del bacilo de Hansen es más común bajo condiciones de contacto más cercano, con el riesgo más alto para aquellos que comparten la misma cama, seguidos por los que viven en la misma casa (6). Para infectarse con el bacilo de Hansen y desarrollar la enfermedad hay, entonces, mayores posibilidades cuando existe un contacto íntimo y repetido (1-6), muy evidente en los casos de lepra infantil, especialmente el contacto madre-hijo (5). Pocas veces se menciona la lepra conyugal, que representa una circunstancia ideal de contacto íntimo para la transmisión de la enfermedad.

El objetivo general de este trabajo retrospectivo de casos fue analizar la presencia de lepra entre cónyuges del departamento del Atlántico, en la Costa Caribe colombiana. Los objetivos específicos fueron determinar la forma clínica asociada con mayor frecuencia de lepra en los cónyuges de los casos índices, así como la relación entre el tiempo de convivencia y la aparición de la enfermedad, precisar si había consanguinidad entre la pareja enferma y describir el grado de discapacidad en el caso índice y en el secundario. El propósito del estudio fue medir el impacto de esta variedad de la enfermedad en la comunidad y analizar la actividad del Programa de Control de Lepra (PCL) que condujo a la detección del caso secundario. No hay datos colombianos sobre esta modalidad epidemiológica de la lepra.

\section{MATERIALES Y METODOS}

Realizamos un estudio retrospectivo, descriptivo, de los casos de lepra conyugal que se presentaron en el Departamento del Atlántico, desde enero de 1980 hasta marzo del 2000, utilizando la historia clínica existente en el PCL. Se analizaron 963 historias clínicas de las 1045 registradas en el programa de lepra; las 82 restantes fueron irrecuperables después de una inundación que comprometió la oficina que las albergaba y se determinó en cuales había 
afección de ambos cónyuges, definidos como la pareja estable durante más de dos años, con la cual se hacía una vida marital y se compartía una habitación. En cada historia clínica se analizaron las siguientes variables: edad, sexo, origen, procedencia, fuente de contagio, forma clínica, tiempo de evolución, ocupación, tiempo de convivencia, consanguinidad, fecha de ingreso al programa, forma de búsqueda del caso y grado de discapacidad. Los pacientes se localizaron de nuevo para confirmar su estado actual, para evaluación de su enfermedad, para confirmar su tiempo de convivencia y para precisar el tiempo transcurrido entre la aparición de la enfermedad en los dos cónyuges. Se les informó sobre la naturaleza confidencial, no intervencionista y sin riesgo alguno del estudio. Se obtuvieron medidas de tendencia central y medidas de dispersión de los principales hallazgos encontrados, los cuales se procesaron en EPI/Info.

Se definió como caso índice o primario al cónyuge que presentó la lepra en primer lugar y como caso secundario, al cónyuge que la presentó luego de convivir como pareja estable con el caso primario.

\section{RESULTADOS}

Se encontraron 26 parejas de cónyuges con lepra, correspondientes al 5,4 \% de los casos detectados con esta enfermedad durante el periodo de estudio. Tenían edades entre 20 y 89 años, con grupos principales entre 30-39 y 4049 años (23,1 \% cada uno), con una media de 48,4. El caso índice fue masculino en un 65,4 \%. La ocupación del caso primario fue hogar (31 \%), agricultor y obrero (23\%), comerciante (15\%) y profesional (8\%.) La ocupación del caso secundario fue hogar (52\%), agricultor (20\%), comerciante (16\%), oficios varios (4\%) y profesor (4\%).

Consideramos como tiempo de evolución de la enfermedad el concepto subjetivo del paciente en relación con la aparición de sus signos y síntomas y el momento en que se establece el diagnóstico; en el 61,5 \% de los casos primarios o índices la evolución fue menor de 2 años; en el 30,7 \% de los casos entre 3 y 5 años y en el 7,6 \% entre 6-8 años. Para el caso secundario, el tiempo de evolución de la enfermedad entre 3 meses y 2 años, estuvo presente en el $88,4 \%$ de los pacientes.

Veintidós casos índices (84,6 \%) presentaron lepra lepromatosa; dos pacientes tenían lepra indeterminada y dos lepra tuberculoide. Once casos secundarios $(42,3 \%)$ presentaron la forma tuberculoide, seguidos de 5 pa- 
cientes $(19,2 \%)$ para cada una de las formas clínicas restantes (indeterminada, dimorfa y lepromatosa), es decir, 16 de los 26 cónyuges secundarios (61,5 \%) fueron paucibacilares.

La consanguinidad sólo estuvo presente en dos parejas, que eran primos.

El tiempo de convivencia de los cónyuges luego de establecida la enfermedad en el caso índice fue de 5 años para dos parejas, de 6 a 10 años para 5, de 11 a 15 años para 6, de 16 a 20 años para dos, de 21-25 para tres, de 26-30 para dos y de 31-40 para seis parejas.. Ninguno de los cónyuges llegó enfermo al matrimonio. No hubo relación entre el tiempo de convivencia y la forma clínica de la enfermedad.

En relación con las discapacidades de las manos del caso índice, se presentó anestesia en 9 casos (grado I, 30,8 \%) y alteración funcional en 4 pacientes (grado II, 15,5\%.). El 50 \% de los casos no presentó ningún grado de discapacidad. En los pies, el 50\% presentaban discapacidad grado I, 3 pacientes presentaron perforante plantar (11,5\%) y el 38,5\% de los casos no presentaban discapacidad. En los ojos, el $80 \%$ de los casos no presentaban alteraciones. Tres pacientes presentaron anestesia de la córnea (11,5 \%).

En las manos, el 80,8 \% de los casos secundarios no presentaron discapacidad, 3 pacientes (11,5\%) presentaron anestesia (discapacidad grado I) y 2 pacientes (7,7 \%) tuvieron discapacidad grado II (deformidad visible). En los pies, 22 pacientes $(84,6 \%)$ no presentaron alteraciones; tres pacientes $(11,5$ $\%)$ tuvieron discapacidad grado I y uno, grado II. En los ojos, 25 pacientes (96,2 \%) no presentaron discapacidad, y sólo un paciente la tuvo de grado II.

La discapacidad fue más frecuente en los hombres: once tuvieron algún grado de ésta en las manos; en los pies, 13 hombres y 8 mujeres la presentaron y en los ojos, 5 hombres y sólo 2 mujeres la tenían en algún grado.

$\mathrm{Ni}$ los dimorfos ni los indeterminados presentaron discapacidad en las manos. La grado I sólo se encontró en la lepra lepromatosa y la grado II, en 5 casos de lepra lepromatosa y en 2 de lepra tuberculoide. En los pies, 16 pacientes lepromatosos presentaron discapacidad grado I y 5 tuvieron discapacidad grado II, tres lepromatosos y 2 tuberculoides.

Los pacientes lepromatosos fueron los únicos que presentaron discapacidad en los ojos, 3 grado I y dos grado II.

En relación con la forma de búsqueda, 18 pacientes fueron hallados por consulta espontánea, 20 en el examen de convivientes y 14 por investigación 
de los contactos sociales, que consistió en la búsqueda activa de enfermos en las comunidades donde había un caso de lepra, no limitada sólo a los convivientes. Los hombres enfermos de lepra se detectaron principalmente por consulta espontánea (12 pacientes) y la mujer, por examen de convivientes (13 pacientes).

La lepra lepromatosa predominó en la mayoría de los grupos etáreos, excepto en el de 50 a 59 años, donde lo hizo la tuberculoide. Los pacientes mayores de 70 años sólo desarrollaron lepra lepromatosa o tuberculoide.

\section{DISCUSIÓN}

Noorden, en relación con el riesgo de adquirir lepra para el contacto conyugal de un enfermo, señala la baja rata de transmisión entre esposos, que oscila entre el 0,3 \% en Japón, 5,5 \% en India y 7,8 \% en Brasil (1). En México fue del $3 \%$ (7) y representó el 5,4 \% de los casos en nuestro estudio, lo que no debe confundirse con la frecuencia de la lepra entre cónyuges, uno sano y otro enfermo, investigación que no pudimos realizar. La baja patogenicidad de $M$. leprae y la alta resistencia de los adultos ante la bacteria, conducen a que pocos cónyuges contraigan la enfermedad, a pesar del contacto íntimo, repetido y directo. Varios estudios de seguimiento de contactos muestran la ocurrencia de lepra en casos secundarios como hijos o hermanos, pero muy poco se menciona al cónyuge (1-6). En 98 familias con un miembro enfermo de lepra, sólo existía un caso de lepra conyugal (8); entre 410 contactos de 120 casos índices seguidos durante 5 años, 14 personas desarrollaron la enfermedad y en ese grupo sólo 2 eran esposos (9). En Cuba, en cinco años de seguimiento, no se detectaron cónyuges como fuente de infección, pero si un familiar como el padre o la madre (10).

El caso índice en nuestra casuística fue de sexo masculino en el 65,4 \% de los casos, lo que refleja la mayor frecuencia de la enfermedad en el hombre (2:1). Similar porcentaje ocurre en México: 67 \% (7). Nuestras parejas provenían principalmente de la ciudad de Barranquilla, manteniendo el patrón urbano del comportamiento epidemiológico de la lepra en el departamento del Atlántico.

La fuente de emisión bacilar que permitiría la transmisión de la enfermedad está representada por las goticas de Pflluge, emanadas de la nariz y de la boca, que persisten durante 10 minutos, con un radio de acción de un metro (11). Pueden ser igualmente fuente de infección las mucosas, sobre todo la boca, así como la secreción sudorípara y láctea $(1,11)$. La infección leprosa por contacto sexual es admitida por diversos autores, pues se encuen- 
tran bacilos en el esperma (12) y se ha informado la presencia de $M$. leprae en la mucosa vaginal y en la vulva del $27 \%$ de mujeres con lepra, así como en el glande y en el prepucio (11). Aunque se han descrito lesiones de lepra en los genitales masculinos $(13,14)$, estas no son frecuentes y la rareza de la lepra conyugal descrita nos inclina a pensar que la transmisión por esta vía es poco probable.

Por otra parte, la transmisión indirecta del bacilo es otra posibilidad porque sobrevive durante días y hasta 5 meses en el medio ambiente, con mejores posibilidades en condiciones favorables de humedad y temperatura (15). No es pues improbable que el piso, los utensilios de cama y del baño alberguen bacilos capaces de ser otra fuente de contagio.

En Libia, la lepra conyugal ocurrió en el 32 \% de 269 parejas con historia positiva de consanguinidad y en el $2,87 \%$ de los casos sin este antecedente (16). Esto hace más probable la susceptibilidad genética para contraer la enfermedad, como se ha descrito en familias de Vietnam del Sur (17). En nuestros pacientes la consanguinidad de los cónyuges sólo estuvo presente en dos parejas y no fue un criterio llamativo de la frecuencia de la enfermedad entre ellos.

La lepra lepromatosa fue la forma clínica más frecuente en el caso índice (84,6 \%), constatándose así como la más infectante y el mayor factor predisponerte para que el segundo cónyuge desarrollara la lepra. Destacamos que hubo dos casos índices de lepra indeterminada y dos de lepra tuberculoide, cuyas parejas desarrollaron igual forma clínica, observaciones que sugieren la transmisión de la lepra a partir de pacientes paucibacilares.

El caso secundario tuvo con mayor frecuencia lepra tuberculoide (42,3 \%) y 61,5 \% fueron paucibacilares. Nunca se presentó un cónyuge paucibacilar como caso índice, cuyo cónyuge desarrollara lepra multibacilar. Este comportamiento es el informado en los casos de lepra conyugal $(7,16)$.

Ningún caso índice llegó enfermo al matrimonio. El tiempo de convivencia de los cónyuges, luego de detectada la enfermedad en el caso primario, varió entre 5 y 40 años, un hallazgo significativo, que revela un periodo de incubación prolongado. En otro estudio de contactos, este periodo estuvo entre 1 y 55 años, con un promedio de 23 (18). Indica que el cónyuge sano sigue en riesgo de desarrollar la enfermedad, inclusive después de tratado el caso índice, y que, como otros contactos, debe ser candidato a estudios de infección subclínica, como los de PCR para demostrar la presencia de ADN 
bacilar en el moco nasal o en la piel, los títulos de IgM antiglicolípido fenólico del bacilo y la reacción de Mitsuda como indicador pronóstico (19).

El largo tiempo de convivencia no es importante para la forma clínica, porque el caso índice lepromatoso y el caso secundario tuberculoide desarrollaron la enfermedad luego del mismo tiempo de convivencia. En México la convivencia antes de desarrollar la enfermedad estuvo entre 11 y 20 años (7).

La forma clínica que más discapacitó fue la lepromatosa, tanto en las manos como en los pies y los ojos. Las discapacidades en el cónyuge afectado inicialmente son más frecuentes y graves que en el caso secundario, porque su enfermedad lleva mayor tiempo de evolución. En términos generales, el pie fue el blanco de mayor grado de discapacidad, lo cual nos obliga a incrementar nuestra campaña de prevención, sabiendo que es secundaria a las actividades laborales, (agricultor, comerciante, vendedor). El caso secundario muestra menor discapacidad porque fue detectado tempranamente y por la información que recibe de su cónyuge.

Los cónyuges afectados secundariamente se encontraron en proporciones equivalentes por los tres métodos, consulta, examen de convivientes e investigación de contactos sociales, lo cual muestra la eficiencia del programa en la búsqueda de casos nuevos .

\section{REFERENCIAS}

1. Noorden SK. The epidemiology of leprosy. In: Hasting, RC. Ed. Leprosy. London: Churchill Livingstone. Chap 2; 1985. p. 15-30.

2. Van Beers SM, Hatta M, Klatser PR. Patient contact is the major determinant in incident leprosy: implications for future control. Int J Lepr other Mycobact Dis 1999; 67: 119-28.

3. Jessudasan K, Bradley D, Smith PG, Christian M. Time trends in the analysis of incidence rate of leprosy among household contacts. Indian J Lepr 1984; 56: 792-806.

4. Sundar Rao PS, Jessudasan K, Mani K, Christian M. Impact of MDT on incidence rates of leprosy among household contacts. Part 1. Baseline data. Int J Lepr other Mycobact Dis 1989; 57: 647-51.

5. Arrieta R, Garcés MT, Ordóñez N, Fadul S, Pinto R, Rodríguez G. Lepra familiar. Biomédica 2001, 21: 248-55. Reproducido en Rev Leprol Fontilles 2002; 23: 421-31. 
6. Fine PEM, Sterne JAC, Ponnighaus JM, Bliss L, Saul J, Chihana A, et al. Household and dwelling contact as risk factor for leprosy in Northern Malawi. Am J Epidemiol 1997; 146: 91-102.

7. Aguirre-Negrette, G. Ramírez-Soltero, S. Lepra conyugal. Dermatol Rev Mex 1990; 34: 273-276.

8. Ashamalla, L. Impact of leprosy on family and intimate relationships. Int J Dermatol 1987; 26: 305-7.

9. George, R, Rao PSS, Mathai R, Jacob M. Intrafamilial transmission of leprosy in Vellore Town, India. Int J Lepr other Mycobact Dis 1993; 61: 550-5.

10. Torres, T. Carrazana, G. Modo de detección y fuente de infección de la incidencia de lepra. Rev Leprol Fontilles 1997; 21:161-5.

11. De las Aguas, T. Consideraciones epidemiológicas sobre la lepra. Rev Leprol Fontilles 1998; 21: 435-460.

12. Abraham, A, Kaur, S, Sharma, V. Acid-fast bacilli in semen; correlation with bacterial index. Int J Lepr other Mycobact Dis 1990; 58: 466-8.

13. Shaw IN, Ebenezer G, Rao GS. Leprosy lesion of the prepuce of the male genitalia: a case report. Lepr Rev 2002; 73: 276-8.

14. Kumar B, Kaur I, Rai R, Mandal SK, Sharma VK. Involvement of male genitalia in leprosy. Lepr Rev 2001; 72: 70-7.

15. Desikan KV, Srivastava G. Extended studies on the viability of Mycobacterium leprae outside the human body. Lepr Rev 1995; 66: 287-95.

16. El-orf, A, Stugh AM. Conyugal leprosy among Libian patients. Dermatology 1989; 196: 271-2.

17. Mira MT, Alcais A, van Thuc N, Thai V, Huong H, Ba NN et al. Chromosome $6 q 25$ is linked to susceptibility to leprosy in a Vietnamese population. Nature Genet 2003; 33:412-15.

18. Shumin C, Lin Z, Diangchang L, Bing L. Should household contact examination in a low endemic situation of leprosy continue? Int J Lepr other Mycobact Dis 2003, 71: 95-100.

19. Bakker Mi, Hatta M, Kwenang A, Faber WR, Beers SM, Klatser PR et al. Population survey to determine risk factors for Mycobacterium lepra transmission and infection. Int J Epidemiol 2004, 33: 1-8. 